\title{
INVASIVE PNEUMOCOCCAL DISEASE, NSW, 2002
}

\author{
Robyn Gilmour \\ Communicable Diseases Branch \\ NSW Department of Health
}

\section{BACKGROUND}

Infection with the bacterium Streptococcus pneumoniae is a major cause of morbidity and mortality in both developed and developing countries. Streptococcus pneumoniae is often found in the upper respiratory tract and can spread directly from the nose and throat to cause invasive infections such as bacteraemia and bacterial meningitis. ${ }^{1,2}$ Those at greatest risk of invasive disease are young children, the elderly, and people with underlying illness. ${ }^{1}$ The rapid increase in the development of resistance to penicillin has raised concerns about the treatment and prevention of pneumococcal infections. With the impending release of the conjugate pneumococcal vaccine into the routine childhood vaccination schedule in 2005, there has been a strong emphasis on collecting information about those cases most at risk for invasive disease as well as baseline data so as to monitor the impact of pneumococcal vaccination in both children and the elderly. ${ }^{3}$

There are 90 different pneumococcal serotypes. The most common serotypes are represented by the 23-valent polysaccharide vaccine for adults. A second conjugate vaccine has been developed for infants, and this formulation contains polysaccharides of the 7 serotypes that commonly affect children.

Invasive pneumococcal disease is identified by the isolation of Streptococcus pneumoniae from the culture of any normally sterile site, including blood, cerebral spinal fluid, pleural fluid, joint fluid, and peritoneal fluid. Since January 2001, all laboratories in NSW have been required under the NSW Public Health Act 1991 to notify cases of invasive pneumococcal disease to their local public health unit. ${ }^{4}$

This article describes the epidemiology of invasive pneumococcal disease in New South Wales, based on data collected from notifications and through enhanced surveillance in 2002.

\section{METHODS}

NSW microbiology laboratories notified cases of invasive pneumococcal disease to their local public health unit. Public health units entered the demographic information for each case onto the NSW Notifiable Disease Database, which is maintained by the Communicable Diseases Branch of the NSW Department of Health. Pneumococcal isolates were sent by the laboratories to the Microbiology
Department at the Children's Hospital at Westmead for serotyping.

In 2002, metropolitan laboratories were audited by either the Children's Hospital at Westmead or by public health units to ensure the complete ascertainment of cases. However, laboratories in rural areas were not audited routinely and only those rural cases notified to the public health unit are presented and analysed here.

\section{Enhanced surveillance for invasive pneumococcal disease in 2002}

In 2002, NSW public health units undertook enhanced surveillance for invasive pneumococcal disease. This involved administering a standardised questionnaire to those involved in the notification of a case. Information about risk factors and immunisation status was collected from the treating clinicians, from hospital records, and through interviews with the cases. Predisposing conditions for invasive pneumococcal disease that were included on the questionnaire were: asplenia; a compromised immune system; chronic cardiac, renal, or pulmonary disease; diabetes; alcohol-related problems; chronic liver disease; premature birth; and congenital or chromosomal abnormalities. $^{5}$

The data collected through this enhanced surveillance were mailed to the Communicable Diseases Branch, NSW Department of Health, and entered onto the NSW Enhanced Invasive Pneumococcal Disease Surveillance Database.

We analysed notifications of invasive pneumococcal disease in NSW for the year 2002 by age, sex, and area of residence. Direct age standardisation was used to compare rates of the disease in different geographical areas. Rates were calculated using Australian Bureau of Statistics estimated residential populations for $2001 .^{6}$

Enhanced surveillance data were collected for notifications in people aged under 5 years and over 50 . Crude rates were calculated for these groups. Enhanced surveillance was not undertaken for notifications in people aged 5 to 49 years.

Both the Hunter and Illawarra area health services were included within the Greater Sydney region so that direct comparisons could be made with data collected before 2002..$^{7,8}$

\section{RESULTS}

During 2002, a total of 870 cases of invasive pneumococcal disease was reported in NSW, representing an annual crude rate of 13.5 per 100,000 people. 
Laboratories notified 851 cases directly to public health units. Seven hundred and forty-one (85 per cent) isolates were sent to the Microbiology Department of the Children's Hospital at Westmead by the laboratory that first made the diagnosis for confirmatory testing and serotyping.

\section{TABLE 1}

AGE AND SEX OF CASES OF INVASIVE PNEUMOCOCCAL DISEASE, NSW, $2002(n=870)$

\begin{tabular}{|lrrc|}
\hline $\begin{array}{c}\text { Age group } \\
\text { (years) }\end{array}$ & \multicolumn{2}{c}{ Cases } & $\begin{array}{c}\text { Incidence } \\
\text { per 100,000 }\end{array}$ \\
\hline $0-<1$ & 60 & 6.9 & 70.3 \\
$1-<2$ & 101 & 11.6 & 118.4 \\
$2-4$ & 104 & 12.0 & 40.1 \\
$5-49$ & 202 & 23.2 & 4.8 \\
$50-64$ & 129 & 14.8 & 12.8 \\
$65-79$ & 150 & 17.2 & 23.6 \\
$80+$ & 124 & 14.3 & 63.8 \\
Sex & 495 & 57.0 & 15.4 \\
Male & 375 & 43.0 & 11.5 \\
Female & Not & & \\
\hline \multirow{2}{*}{ Source: } & NSW Notifiable Diseases Database, \\
& Communicable Disease Branch, NSW Department \\
& of Health & \\
\hline
\end{tabular}

Highest crude rates of notification were among: children aged 1-2 years; children aged less than 1 year; and adults aged more than 80 years (Table 1). The male-to-female ratio was $1.3: 1$. The majority of cases notified ( 87 per cent) were residents of the Greater Sydney region. Within the Greater Sydney region the Hunter Area Health Service had the highest overall age-standardised rate of invasive pneumococcal disease, and the lowest was reported in the South Western Sydney Area Health Service. The crude notification rate of the disease in rural NSW was generally lower than that for the Greater Sydney region (Table 2).

In 2002, the average number of cases reported each month was 72 (range 28-87). A seasonal pattern was identified, with the greatest incidence occurring from July to September in many area health services.

\section{Enhanced surveillance data}

Enhanced surveillance data were collected for 668 of the 870 notified cases (77 per cent); 265 of these cases were children aged less than 5 years and 403 of these cases were adults aged 50 years and over. Sixty-two per cent of the children were male (male:female ratio $=1.6: 1$ ), as were 53 per cent of adults (male:female ratio $=1.1: 1$ ). The Western Sydney Area Health Service had the highest crude rate among children under 5. The South Western Sydney

\section{TABLE 2}

\section{NOTIFICATION OF INVASIVE PNEUMOCOCCAL DISEASE IN AREA HEALTH SERVICES, CHILDREN AGED UNDER 5 YEARS, ADULTS AGED OVER 50 YEARS, AND ALL AGES, NSW, 2002}

\begin{tabular}{|c|c|c|c|c|c|c|}
\hline \multirow[b]{2}{*}{ Area health service } & \multicolumn{2}{|c|}{ Age $<5$ years } & \multicolumn{2}{|c|}{ Age $\geq 50$ years } & \multicolumn{2}{|r|}{ All ages } \\
\hline & $n$ & Crude rate* & $n$ & Crude rate* & $n$ & Standardised rate* \\
\hline \multicolumn{7}{|l|}{ Greater Sydney region } \\
\hline Central Coast & 13 & 65.7 & 27 & 28.2 & 51 & 14.4 \\
\hline Central Sydney & 18 & 60.7 & 41 & 31.3 & 74 & 15.7 \\
\hline Hunter & 27 & 75.8 & 61 & 38.1 & 105 & 19.0 \\
\hline Illawarra & 15 & 65.4 & 28 & 26.2 & 53 & 14.8 \\
\hline Northern Sydney & 34 & 76.4 & 47 & 19.7 & 101 & 13.2 \\
\hline South Eastern Sydney & 31 & 70.9 & 57 & 25.6 & 116 & 15.3 \\
\hline South Western Sydney & 34 & 55.2 & 31 & 16.9 & 93 & 12.1 \\
\hline Wentworth & 19 & 78.7 & 18 & 25.3 & 50 & 17.2 \\
\hline Western Sydney & 46 & 88.5 & 33 & 19.5 & 113 & 16.6 \\
\hline \multicolumn{7}{|l|}{ Rural NSW } \\
\hline Far Western & 2 & 59.1 & 4 & 27.6 & 9 & 19.0 \\
\hline Greater Murray & 5 & 27.5 & 19 & 25.4 & 26 & 9.8 \\
\hline Macquarie & 3 & 37.8 & 6 & 20.0 & 13 & 12.3 \\
\hline Mid North Coast & 6 & 39.3 & 5 & 5.3 & 14 & 5.5 \\
\hline Mid Western & 7 & 60.5 & 12 & 24.4 & 22 & 12.9 \\
\hline New England & 2 & 16.8 & 1 & 1.9 & 3 & 2.3 \\
\hline Northern Rivers & 1 & 6.2 & 2 & 2.4 & 7 & 2.3 \\
\hline Southern & 1 & 8.5 & 9 & 15.2 & 17 & 9.1 \\
\hline Other & 1 & & 2 & & 3 & \\
\hline Total & 265 & 61.6 & 403 & 21.9 & 870 & \\
\hline
\end{tabular}


TABLE 3

RELATIVE RISK OF DEATH FROM INVASIVE PNEUMOCOCCAL DISEASE

FOR ADULTS AGED 50 YEARS AND OVER WITH PREDISPOSING CONDITIONS COMPARED WITH ADULTS WITH NO PREDISPOSING CONDITIONS, NSW, 2002

\begin{tabular}{|lccc|}
\hline Pre-existing condition & Relative risk & $\mathbf{( 9 5 \%} \mathbf{~ C l )}$ & $\boldsymbol{P}$ value \\
\hline No predisposing condition & Referent & & \\
Any predisposing condition* & 2.1 & $(1.3-3.4)$ & $<0.010$ \\
Cardiac disease & 2.7 & $(1.5-4.7)$ & $<0.001$ \\
Immunosuppression & 2.3 & $(1.3-4.0)$ & $<0.010$ \\
Renal disease & 2.3 & $(1.0-5.5)$ & 0.070 \\
Respiratory disease & 1.5 & $(0.7-3.1)$ & 0.300 \\
Diabetes & 1.5 & $(0.7-3.3)$ & 0.300 \\
Alcohol & 1.9 & $(0.5-6.7)$ & 0.400 \\
Asplenia & 1.9 & $(0.3-10.8)$ & 0.500 \\
\hline * as defined by NHMRC & \multicolumn{4}{c}{} \\
Source: NSW Enhanced Invasive Pneumococcal Disease Surveillance Database. \\
\multicolumn{4}{r}{ Communicable Disease Branch, NSW Department of Health } \\
\hline
\end{tabular}

Area Health Service recorded the lowest crude rate in the Greater Sydney region in children under 5 years (Table 2).

Among adults aged over 50 years in the Greater Sydney region, crude rates of invasive pneumococcal disease were highest in the Hunter Area Health Service and lowest in the South Western Sydney Area Health Service (Table 2).

The most common clinical presentation among children was bacteraemia (66 per cent). Pneumonia was the most common presentation in adults (70 per cent). Meningitis was an uncommon presentation in children ( 7.1 per cent) and adults ( 3 per cent).

A predisposing condition, as defined by the National Health and Medical Research Council (NHMRC), ${ }^{5}$ was reported in 14.3 per cent of children. An additional 1 per cent had other medical conditions that required regular review by a general practitioner. In adults aged 50 years and over, 64 per cent had predisposing conditions as defined by the NHMRC and a further 6 per cent had other medical conditions that required regular review by a general practitioner. Data for predisposing conditions were not reported for 7 per cent of adult cases and 3 per cent of children.

Among the 668 cases investigated through enhanced surveillance, 98 deaths ( 15 per cent) were reported. Four children aged under 5 years (1.5 per cent) died. Of these, 2 had predisposing conditions and none had received vaccination. Ninety-four ( 23 per cent) of the adults aged over 50 years died. Adults were more likely to die if they had a predisposing condition as defined by the NHMRC (RR 2.1, $p=<0.01$ ) (Table 3). Of those whose vaccination status was known (70 per cent), only 16 per cent had been vaccinated within the previous 5 years.
Indigenous status was reported for 94 per cent of cases. Fifteen cases (2.4 per cent of enhanced cases) were identified as being either Aboriginal or Torres Strait Islanders, and of these, 73 per cent were from rural NSW.

Vaccination data were complete for 229 (97 per cent) children aged under 5 years. Five children ( 2.2 per cent) are known to have received the vaccine. Of these 5 , the isolate from 1 child matched the serotype represented in the vaccine. The serotypes from the other 4 children were unknown. Vaccination data for adults aged over 50 years were available for 281 (70 per cent) cases. Of these, 61 (22 per cent) were vaccinated within the last 5 years. Eighty per cent reported predisposing conditions.

Of the 5 adult cases that were identified as being Aboriginal people, 3 had received vaccination. The serotype was unknown for 3 cases, and the remaining 2 cases had serotypes represented by the 23 -valent vaccine. Of the 10 Aboriginal children under 5 years, 4 children had received the vaccine; however, only 3 were fully vaccinated for their age and information about serotypes for these cases was unavailable.

Serotyping was available for 535 (80 per cent) cases. Serotyping was not performed on most isolates from rural areas. Of children under 5 years whose serotype data were available, 197 (89 per cent) had serotypes that were represented by the 7-valent conjugate vaccine. In patients aged over 50 years whose serotype data were available, 288 (93 per cent) had serotypes included in the 23 -valent polysaccharide vaccine (Table 4). There were 7 patients whose serotypes were not represented by the vaccine. The serotypes involved with vaccination failures were: $14,4,6 \mathrm{~B}, 9 \mathrm{~V}, 23 \mathrm{~F}, 3,22 \mathrm{~F}, 9 \mathrm{~N}, 10 \mathrm{~A}, 12 \mathrm{~F}, 17 \mathrm{~F}$, and 19F. 
TABLE 4

PERCENTAGE OF ISOLATES FROM CASES OF INVASIVE PNEUMOCOCCAL DISEASE IN SELECTED AGE GROUPS THAT BELONG TO SEROTYPES AND SEROGROUPS COVERED BY CURRENT PNEUMOCOCCAL VACCINES, NSW, 2002

\begin{tabular}{|c|c|c|c|c|c|}
\hline \multirow[b]{2}{*}{$\begin{array}{l}\text { Age group } \\
\text { (years) }\end{array}$} & \multirow[b]{2}{*}{$\begin{array}{c}\text { Number of } \\
\text { isolates }\end{array}$} & \multicolumn{2}{|c|}{ 7-valent paediatric vaccine* } & \multicolumn{2}{|c|}{ 23-valent adult vaccine \# } \\
\hline & & $\begin{array}{l}\text { Percentage of } \\
\text { isolates with the } \\
\text { same serotype } \\
\text { as the vaccine }\end{array}$ & $\begin{array}{l}\text { Percentage of } \\
\text { isolates with the } \\
\text { same serogroup } \\
\text { as the vaccine }\end{array}$ & $\begin{array}{l}\text { Percentage of } \\
\text { isolates with the } \\
\text { same serotype } \\
\text { as the vaccine }\end{array}$ & $\begin{array}{l}\text { Percentage of } \\
\text { isolates with the } \\
\text { same serogroup } \\
\text { as the vaccine }\end{array}$ \\
\hline $0-1$ & 131 & 88 & 95 & - & - \\
\hline $2-4$ & 90 & 91 & 96 & - & - \\
\hline $50-64$ & 103 & - & - & 96 & 99 \\
\hline$\geq 65$ & 211 & - & - & 91 & 97 \\
\hline \multicolumn{6}{|c|}{$\begin{array}{l}\text { * Serotypes in the } 7 \text {-valent conjugate vaccine are } 4,6 \mathrm{~B}, 9 \mathrm{~V}, 14,18 \mathrm{C}, 19 \mathrm{~F} \text { and } 23 \mathrm{~F} \text {. } \\
\text { \# Additional serotypes in the 23-valent vaccine are 1, 2, 3, 5, 7F, 8, 9N, 10A, 11A, 12F, 15B, 19A, 20, 22F and 33F. } \\
\text { Source: Microbiology Department, the Children's Hospital at Westmead. }\end{array}$} \\
\hline
\end{tabular}

\section{DISCUSSION}

Invasive pneumococcal disease causes a significant burden of disease in NSW. The data presented here show that children under 2 years and adults over 80 years are the most affected. The incidence of the disease demonstrates a seasonal variation, with the majority of cases occurring in the coldest months.

Before invasive pneumococcal disease became notifiable in NSW, the mechanisms for laboratory reporting were established only in the Greater Sydney region. While this limits data comparison to within this region, data from this region are accurate, as routine audits were conducted regularly. ${ }^{7}$ Notifications by laboratories in rural regions of NSW may have been incomplete, as audits were not routinely carried out and underreporting may have occurred.

Within rural NSW, the incidence of invasive pneumococcal disease varied in different regions. Rates were higher in the Far Western and Mid Western area health services than in other rural areas. Rates were lowest in northern NSW, but because of the small numbers of notifications received in rural areas, it is difficult to draw conclusions about the incidence in rural NSW. Underreporting in some areas is a concern, as the incidence of disease may be higher than reported here. As the public health units implement regular laboratory audits, and laboratories forward isolates for serotyping at the Children's Hospital at Westmead, reporting of cases of invasive pneumococcal disease should improve.

Comparing data collected in 2001 and 2002 from the Greater Sydney region, ${ }^{8}$ there was a 14 per cent increase in the number of cases aged under 5 and over 50 years. In 2002 , there was an increase in invasive pneumococcal disease in children aged less than 1 year (from 93.0 to 118.4 per 100,000 population) and in adults aged 50 to
64 years (from 9.1 to 12.8 per 100,000 population). The Hunter Area Health Service had the largest increase, with notifications rising by 40 per cent; for children under 5 years of age there was an increase from 53.3 to 75.8 per 100,000 and for adults over 50 years an increase from 20.6 to 38.1 per 100,000 population. Even though the disease became notifiable in 2002, reporting mechanisms have remained relatively unchanged in the Hunter region. Over the past 4.5 years, the Hunter region has had an average disease incidence of 10.1 per 100000 population. ${ }^{7}$ Examination of data collected for 2003 will determine whether this is a real increase in disease incidence. In 2003, the Hunter encouraged general practitioners to vaccinate patients 65 years and over and subsequent data from 2003 indicates a lower rate of disease in this region.

Notifications are highest in children aged under 2 years. This may be related to the immaturity of their immune systems. Comparison with previous data for NSW shows an increase in disease incidence. ${ }^{7,8}$ Currently, only a small proportion of children in this age group are vaccinated with the pneumococcal vaccine, as the 7-valent vaccine has only been available since late 2001. Notifications for invasive pneumococcal disease in adults aged 50-64 years remain low despite a small increase since 2001.

The distribution of serotypes in this surveillance period mirrors that previously reported for the Greater Sydney region. ${ }^{7}$ The predominant serotype for both children under 5 and adults over 50 was serotype 14 . Children were more likely to have a higher percentage of serotypes $19 \mathrm{~F}$ and $6 \mathrm{~B}$, whereas in adults there were more cases with serotypes 4 and 23F. Infection with serotype 14 resulted in a higher percentage of cases with meningitis (44 per cent) in children aged under 5 years. In 2002, up to 97 per cent of patients with invasive pneumococcal disease in NSW have infections caused by Streptococcus pneumoniae serotypes contained in either the 7-valent or 23-valent vaccines. 
A higher risk of death from invasive pneumococcal disease was associated with both increasing age and underlying illness. ${ }^{10}$ Vaccination is currently recommended for adults with a pre-existing condition as defined by the NHMRC, all adults aged 65 years and over and Aboriginal people over 50 years. ${ }^{5}$ Our data suggest that pneumococcal vaccine is under-used among those for whom it is recommended. Eighty-four per cent of cases that either had a pre-existing condition or were aged over 65 years were not vaccinated. Prevention of pneumococcal disease is important, and uptake of the vaccine should be encouraged in the elderly and people with preexisting conditions.

Data describing Aboriginality was available for 94 per cent of patients aged under 5 years and over 50 years. Our data suggested a greater percentage of pneumococcal disease occurred in indigenous people in rural regions of NSW, with a rate of 13.5 per 100,000 compared with 4.5 per 100,000 for non-indigenous people. With pneumococcal vaccination available free of charge for many indigenous people, surveillance of disease will be important over the next few years to monitor vaccine failure and adequacy of vaccine coverage of serotypes isolated from Aboriginal people. It is difficult to draw any conclusions about trends in the incidence of invasive pneumococcal disease in Aboriginal people living in NSW because there are no previous data for comparison.

Conclusions that can be drawn from this review are limited by incomplete data for some important variables. Serotype data was not available for 20 per cent of cases and vaccination status for adults was not available for 30 per cent of cases. No data were available about the uptake of pneumococcal vaccine in NSW communities. In the United States, where the 7-valent vaccine has been available for 2 years, decreased rates of invasive pneumococcal disease have been documented. ${ }^{9}$ Analysis of antibiotic sensitivity data of isolates is currently underway at the Children's Hospital at Westmead and this is likely to provide more useful information. As networks of rural laboratories are established, the quality of surveillance data for all rural cases should improve.

It appears that vaccination is poor among groups where vaccination is not provided free of charge, especially in children under 5 years. Our findings suggest that health care practitioners should encourage vaccination, especially for groups at highest risk for invasive pneumococcal disease. Assessment of the changing burden of the disease in NSW and the effects of pneumococcal immunisation will be possible using these data as a baseline.

\section{ACKNOWLEDGMENTS}

We appreciate the time and efforts from all the public health units and microbiology laboratories across NSW. We would also like to thank Michael Watson and his staff, Microbiology Department, the Children's Hospital at Westmead, for laboratory surveillance and serotyping.

\section{REFERENCES}

1. Gilbert GL. Retreat of the pneumococcus. Med J Aust 2000:173(Suppl): s20-s21.

2. McIntyre P, Gidding H, Gilmour R, Lawrence G, Hull B, Horby $\mathrm{P}$, Wang $\mathrm{H}$, Andrews $\mathrm{R}$, Burgess M. Vaccine preventable diseases and vaccination coverage in Australia, 1999 to 2000. Canberra: Commonwealth Department of Health and Aged Care, 2002.

3. Mulholland EK. Conjugate pneumococcal vaccines: an overview. Med J Aust 2000: 173(Suppl): s48-s50.

4. Communicable Diseases Surveillance and Control Unit. Notifiable disease manual: 5th edition. Sydney: NSW Department of Health, 2000.

5. National Health and Medical Research Council. The Australian immunisation handbook. 8th ed. Canberra: Commonwealth Department of Health and Ageing, 2003.

6. Australian Bureau of Statistics. 2001 community profiles (HOIST). Sydney: Centre for Epidemiology and Research, NSW Department of Health.

7. McIntyre P, Gilmour R, Gilbert G, Kakakios A, Mellis, C. Epidemiology of invasive pneumococcal disease in New South Wales, 1997-1999. Med J Aust 2000: 173(Suppl): s22-s26.

8. McIntyre P, Gilmour R, Watson M. Differences in the epidemiology of invasive pneumococcal disease, metropolitan New South Wales 1997-2001. N S W Public Health Bull 2003:14(4-5): 85-89.

9. Black SB, Shinefield HR, Ling S, Hanan J, Firemas B, Spring D, Noyes J, Lewis E, Ray P, Lee J, Hackell J. Effectiveness of heptavalent pneumococcal conjugate vaccine in children younger than five years of age for prevention of pneumonia. Pediatr Infect Dis J 2002; 21: 810-15.

10. Gilmour R. Associated risk factors of death for pneumococcal disease in New South Wales. Proceedings of the Communicable Disease Control Conference, March 31 to April 1 2003, Canberra, Australia. $\boldsymbol{B}$ 